\title{
UN NUEVO SANTO TOMÁS DE AQUINO DE FRANCISCO PACHECO
}

\section{A NEW PAINTING OF SAINT THOMAS AQUINAS BY FRANCISCO PACHECO}

\author{
Antonio Romero Dorado \\ antonio.romero.dorado@gmail.com
}

\begin{abstract}
El objetivo de este texto es dar a conocer una nueva pintura de Francisco Pacheco (1564-1644). Se trata de una imagen de Santo Tomás de Aquino, firmada y fechada por el artista en 1617.

Palabras clave: Francisco Pacheco; Santo Tomás de Aquino; escuela sevillana; pintura; siglo XVII.

The purpose of this paper is to present a new painting by Francisco Pacheco (1564-1644). It is a depiction of Saint Thomas Aquinas, signed and dated by the artist in 1617.

Keywords: Francisco Pacheco; Saint Thomas Aquinas; Sevillian School; painting; 17th century.
\end{abstract}

Tras la reciente exposición dedicada al pintor Francisco Pacheco (1564-1644) en el Museo de Bellas Artes de Sevilla, titulada Pacheco: teórico, artista, maestro, podemos decir que vivimos momentos de renovado interés por su figura ${ }^{1}$. A pesar del necesario y encomiable esfuerzo realizado por el museo, parece difícil que la imagen del artista se libere por completo de los tópicos que arrastra. Su faceta como maestro de Velázquez y de Alonso Cano, que debería haber engrandecido su personalidad, por el contrario, la ha empequeñecido notablemente. Lo lógico sería que Pacheco fuera comparado con los otros pintores sevillanos de su generación, como Alonso Vázquez. Sin embargo, cuando se habla de su supuesta mediocridad como pintor $^{2}$, de forma implícita se está comparando su capacidad artística con la de ambos discípulos suyos, que grosso modo eran treinta y cinco años más jóvenes que él. Asimismo, otro aspecto que paradójicamente ha ido en su contra es su importante

${ }^{1}$ AA.VV.: Pacheco. Teórico, artista, maestro. Sevilla, 2016.

2 JUSTI, Carl: Velázquez y su siglo. Madrid, 1999, p. 83; y LAFUENTE FERRARI, Enrique: Breve historia de la pintura española. T. 2. Madrid, 1987, p. 302. 
labor como teórico y literato. Esto, lejos de perfilar una personalidad polifacética singular, con frecuencia se ha esgrimido para compensar su presunta falta de pericia artística. Francamente, la severidad y el anacronismo con que se juzga a Pacheco son verdaderamente impropios de la historiografía científica.

Sin profundizar en estos clichés, pero partiendo de estas consideraciones previas, con este texto queremos contribuir al catálogo del pintor presentando una nueva obra. Se trata de una pintura al óleo sobre lienzo que representa a Santo Tomás de Aquino y que se encuentra en Sanlúcar de Barrameda, en la iglesia de Santo Domingo de Guzmán (Figura 1)33. La pintura, además de presentar con claridad el estilo de Pacheco, está firmada por él y aparece fechada en 1617. En esta ocasión, el artista ha rubricado su creación mediante el habitual monograma "OFP" -"Opus Francisco Pacheco"-, debajo del cual se leen los números "617" (Figura 2)4. La obra se encuentra en la capilla de la Virgen del Rosario, que está situada en el crucero de la antigua iglesia conventual, hoy parroquial, concretamente en el lado de la epístola. Por el momento no es posible aportar las dimensiones exactas de la tela, ya que se encuentra ubicada a una gran altura. De hecho, está encastrada en el ático de un retablo situado en el testero derecho de la citada capilla del Rosario (Figura 3). Este retablo es una estructura del último cuarto del siglo XVIII ${ }^{5}$, cuya hornacina central alberga una imagen escultórica del arcángel San Rafael. No obstante el emplazamiento, a simple vista podemos calcular que aproximadamente mide unos 100 x $80 \mathrm{~cm}$. Sin duda, su situación en un retablo muy posterior y su elevada posición han hecho que la obra haya pasado completamente desapercibida hasta ahora.

La pintura muestra la imagen de medio cuerpo de Santo Tomás de Aquino, representado sobre un fondo neutro de color gris. Como es de esperar, el monje viste el hábito dominico, compuesto por una túnica blanca así como por una capa y una esclavina de color negro. Bajo las mangas de la túnica asoman los puños de la camisa interior, también blanca, y alrededor del cuello se observa el volumen de la capucha que tiene la esclavina. Tanto esta última como la capa están decoradas con pequeños joyeles dorados, de perfil cuadrilobulado, que contienen piedras rojas y negras y que

${ }^{3}$ Sobre la iglesia de Santo Domingo de Sanlúcar, véanse los siguientes títulos: VELÁZQUEZ-GAZTELU, Juan Pedro: Fundaciones de todas las iglesias, conventos y ermitas de la Muy Noble y Muy Leal Ciudad de Sanlúcar de Barrameda. Año de 1758. Sanlúcar, 1995, pp. 187-227; CRUZ ISIDORO, Fernando: "El Convento de Santo Domingo de Sanlúcar de Barrameda: patronazgo de los Guzmanes, proceso constructivo y patrimonio artístico (1528-1605)", Laboratorio de Arte, 23, 2011, p. 79-106; y CRUZ ISIDORO, Fernando: "El patrimonio artístico desamortizado del convento de Santo Domingo de Sanlúcar de Barrameda (1835-1861)", Laboratorio de Arte, 24, 2012, pp. 549-570.

${ }^{4}$ El autor agradece al padre D. Juan Mateos Padilla, párroco de Santo Domingo de Sanlúcar, el permiso para trabajar en la iglesia y realizar las fotografías, así como a D. José María Hermoso Rivero por su imprescindible colaboración.

${ }^{5}$ Las indicaciones sobre este retablo las debo y agradezco a D. José Manuel Moreno Arana, compañero del grupo de investigación HUM171, CIHAA. 
están cosidos a la tela. Sobre los hombros, el santo lleva dos collares que están compuestos por piezas doradas con piedras rojas y negras engarzadas, que son similares a los joyeles cosidos a la ropa que ya hemos citado. Entre ambos collares, en el centro del pecho, se puede ver un pequeño sol dorado, cuyo centro es una cara en torno a la cual aparecen numerosos rayos, que es metáfora de la sabiduría irradiada por el santo. Asimismo, el dominico lleva otros atributos que lo identifican como Doctor de la Iglesia, portando en la mano izquierda una pluma, mientras que en la otra mano sostiene la maqueta de una iglesia, con aspecto de templete. Del cálamo de la pluma sale un fino haz de luz blanca, que llega hasta la puerta de la maqueta de la iglesia. Sobre la cabeza, Santo Tomás lleva un bonete negro adornado con dos borlas blancas, que contrasta con el color más claro de su cara, definida por grandes cejas negras, nariz alargada, boca pequeña y barba gris recortada. Su mirada ensimismada parece conectar con la inspiración que le insufla el Espíritu Santo, representado en el ángulo superior izquierdo, en forma de paloma blanca que vuela entre nubes. Junto a la mano que sostiene la pluma, se observa la firma y la fecha de la obra, pintadas en rojo. En cuanto al estado de conservación de la pintura, parece bastante bueno, salvo por la distensión del lienzo que ha provocado ondulaciones donde se ha acumulado gran cantidad de polvo. En cualquier caso, parece que la obra no tiene grandes repintes a excepción del que se observa en la frente del santo y de otros que se aprecian en el fondo gris. Asimismo, la marca que ha dejado en la tela el travesaño central del bastidor, tampoco interfiere demasiado en la percepción global de la pintura, cuyo barniz no aparenta deterioro, presentando un acabado bastante mate.

Por el momento, no se conocen datos documentales sobre esta obra, si bien podría tratarse de la pintura al óleo sobre lienzo de Santo Tomás de Aquino que en 1835 ya estaba en la iglesia, como se consigna en el inventario realizado dicho año, con motivo de la desamortización del convento ${ }^{6}$. Las medidas del Santo Tomás que por entonces estaba en la iglesia eran de 2 varas de alto por $3 / 4$ de vara de ancho -unos 167 x 62,4 cm-. Evidentemente, estas dimensiones no se corresponden con el formato de la obra que presentamos. Sin embargo, no podemos descartar que la altura de la pintura haya sido modificada para adaptarla al hueco del retablo que la alberga, estructura que no consta en el inventario de 1835 y que podría proceder de otro de los numerosos conventos que fueron desamortizados en Sanlúcar ${ }^{7}$. Lo que no encaja con la pintura actual es la anchura de la obra que aparece en el inventario, pues el documento dice que era menor que la actual, aunque bien podría tratarse de un error del inventario, posiblemente realizado a simple vista.

Lo cierto es que nuestra obra, al estar fechada en 1617, podemos encuadrarla en el tiempo en que don Manuel de Guzmán y Silva, VIII duque de Medina Sidonia, fue titular del patronato del convento de Santo Domingo de Sanlúcar, ciudad que

${ }^{6}$ CRUZ ISIDORO, Fernando: "El patrimonio artístico...”, op. cit., p. 552.

7 VEGAZO PALACIOS, Jesús Miguel: La desamortización eclesiástica en Sanlúcar de Barrameda (1835-1845). Sevilla, 2007. 
era la sede de su corte ducal. Don Manuel fue titular de la casa de Medina Sidonia entre 1615 y $1636^{8}$, periodo durante el cual ejerció un importante patrocinio de obras de arte, ampliando notablemente la colección ducal de pinturas ${ }^{9}$. Nos inclinamos a pensar que nuestra obra bien pudo ser encargo de la comunidad religiosa, del propio duque o de este último a través de los monjes. Asimismo, dentro de la producción de Pacheco, podemos comparar este nuevo Santo Tomás con otras obras suyas de similar cronología, como los Cuatro evangelistas y los Cuatro padres de la Iglesia latina del convento de San Clemente de Sevilla. Estas pinturas, de 1613, no solo son imágenes de santos de medio cuerpo, como la de Sanlúcar, sino que también tienen algunos detalles similares a ella, como son la mano que sostiene la pluma de San Juan y la paloma blanca que insufla a San Gregorio, muy parecidas a las de nuestro Santo Tomás ${ }^{10}$. La misma posición de la mano ya la veíamos en una obra bastante anterior, que es el San Juan del Museo de Bellas Artes de Sevilla, procedente del convento de Pasión, de hacia 1605-1610 ${ }^{11}$. También resulta interesante la comparación del Santo Tomás que presentamos con otras pinturas de bustos de santos realizadas por Pacheco, como la serie de Reyes santos ingleses del colegio de San Albano de Valladolid ${ }^{12}$, de hacia $1601^{13}$, y el San Vicente Ferrer de colección particular madrileña, aunque esta última es obra de madurez, de hacia $1637^{14}$.

Podemos afirmar que en torno a 1617, el año en que está firmada nuestra pintura, Pacheco se encontraba en la cumbre de su carrera. Verdaderamente, la década de 1610 fue crucial dentro de su trayectoria. Por entonces, terminó la serie de cuadros para el claustro grande de la Merced de Sevilla (1600-1611) y pintó obras tan importantes en su producción como la Muerte de San Alberto (1612), San Sebastián

${ }^{8}$ SALAS ALMELA, Luis: Medina Sidonia: el poder de la aristocracia, 1580-1670. Madrid, 2008, pp. 273-307.

9 CRUZ ISIDORO, Fernando: "La colección pictórica del palacio sanluqueño de la casa ducal de Medina Sidonia entre los años de 1588 y 1764". Laboratorio de Arte, 16, 2003, pp. 151-170; y URQUÍZAR HERRERA, Antonio: "Las casas del desengaño, y los límites de las colecciones artísticas de los duques de Medina Sidonia en Sanlúcar de Barrameda", en AA.VV.: El duque de Medina Sidonia. Mecenazgo y renovación estética. Huelva, 2015, pp. 97-118.

10 VALDIVIESO GONZÁLEZ, Enrique y SERRERA CONTRERAS, Juan Miguel: Pintura sevillana del primer tercio del siglo XVII. Madrid, 1985, pp. 16-116, láms. 1-87. Aquí véanse las láms. 30 y 31.

11 AA.VV.: Pacheco. Teórico..., op. cit., p. 188.

12 VALDIVIESO, Enrique: "Una serie de santos reyes de Inglaterra de Francisco Pacheco", Boletín del Seminario de Arte y Arqueología, 60, 1994, pp. 463-470.

13 CANO RIVERO, Ignacio: "Una serie de santas inglesas por Juan de Roelas en Valladolid", en Juan de Roelas. Sevilla. 2008, pp. 82-95.

${ }^{14}$ NAVARRETE, Benito: "Precisiones y adiciones al catálogo de Alonso Vázquez y Francisco Pacheco", Archivo Hispalense, 238, 1995, pp. 149-162. Aquí véanse las pp. 156157 y la fig. 4. 
curado por Santa Irene (1616), su magno Juicio Final (1611) y la pintura que suele considerarse su obra maestra: Cristo servido por los ángeles (1616). Asimismo, durante ese decenio fijó su modelo de Cristo crucificado $(1614,1615)$, tan famoso como denostado, y entraron como aprendices en su taller Diego Velázquez y Alonso Cano, en 1611 y en 1616 respectivamente ${ }^{15}$. Además, ese mismo año de 1616 fue nombrado "alcalde veedor del oficio de pintor"16, cargo que ostentó junto a Juan de Uceda y que le reconoció una innegable autoridad en Sevilla entre los de su oficio.

Pero no todo fueron luces, pues la cresta de la ola, a pesar de estar en lo más alto, empezaba a inclinarse irremediablemente, en una tendencia que a la postre sería imparable. A la nueva vía abierta en Sevilla por Juan de Roelas, que suponía una brusca ruptura con la tradición anterior, llegada desde fuera, se sumaba la figura emergente de Herrera el Viejo. Este último, en esa década de 1610, que fue la primera de su carrera pictórica, partiendo de la tradición tardo-manierista sevillana y de la órbita del propio Pacheco, empezaba a dar claras muestras de renovación. Todo ello sin tan siquiera haberse examinado como maestro pintor, pues ejerció durante años al margen de la ley, hasta que fue examinado, precisamente en 1617, bajo la supervisión de Pacheco ${ }^{17}$. Además, ya entonces, en algunas obras del pintor sanluqueño, empieza a intuirse la mano de sus oficiales. En este sentido resulta bastante elocuente la comparación de nuestro Santo Tomás con otras composiciones de esos mismos años, como el San Francisco y el Santo Domingo de Villamanrique ${ }^{18}$, de hacia 1616-1619. Estas dos obras, recientemente restauradas ${ }^{19}$ y que también son figuras de medio cuerpo de santos mendicantes, revelan en su ejecución una impronta muy distinta a nuestro Santo Tomás, por lo que parecen traslucir lo que con acierto se ha llamado "la enriquecedora experiencia compartida en el taller" 20 . Para finalizar, admitiendo que el Santo Tomás de Aquino que presentamos es una obra menor dentro de la producción del sanluqueño, debemos apuntar que tiene el interés de ser la única de dicha iconografía dominica que aparentemente se conserva de mano de Pacheco, a cuyo catálogo esperamos haber contribuido siquiera modestamente.

Fecha de recepción: 9 de septiembre de 2016

Fecha de aceptación: 4 de abril de 2017

15 VALDIVIESO GONZÁLEZ, E. y SERRERA CONTRERAS, J. M.: Pintura sevillana..., op. cit., pp. 39-40.

${ }_{16}$ Ibidem, p. 40.

${ }_{17}$ MARTÍNEZ RIPOLL, Antonio: Francisco de Herrera el Viejo. Sevilla, 1978, pp. 13-77.

18 VALDIVIESO GONZÁLEZ, E. y SERRERA CONTRERAS, J. M.: Pintura sevillana..., op. cit., lám. 70.

19 http://noticiasgestionarte.blogspot.com.es/2016/04/para-ir-ver-francisco-pachecoteorico.html (Consultado el 8-9-2016).

20 AA.VV.: Pacheco. Teórico..., op. cit., p. 67. 


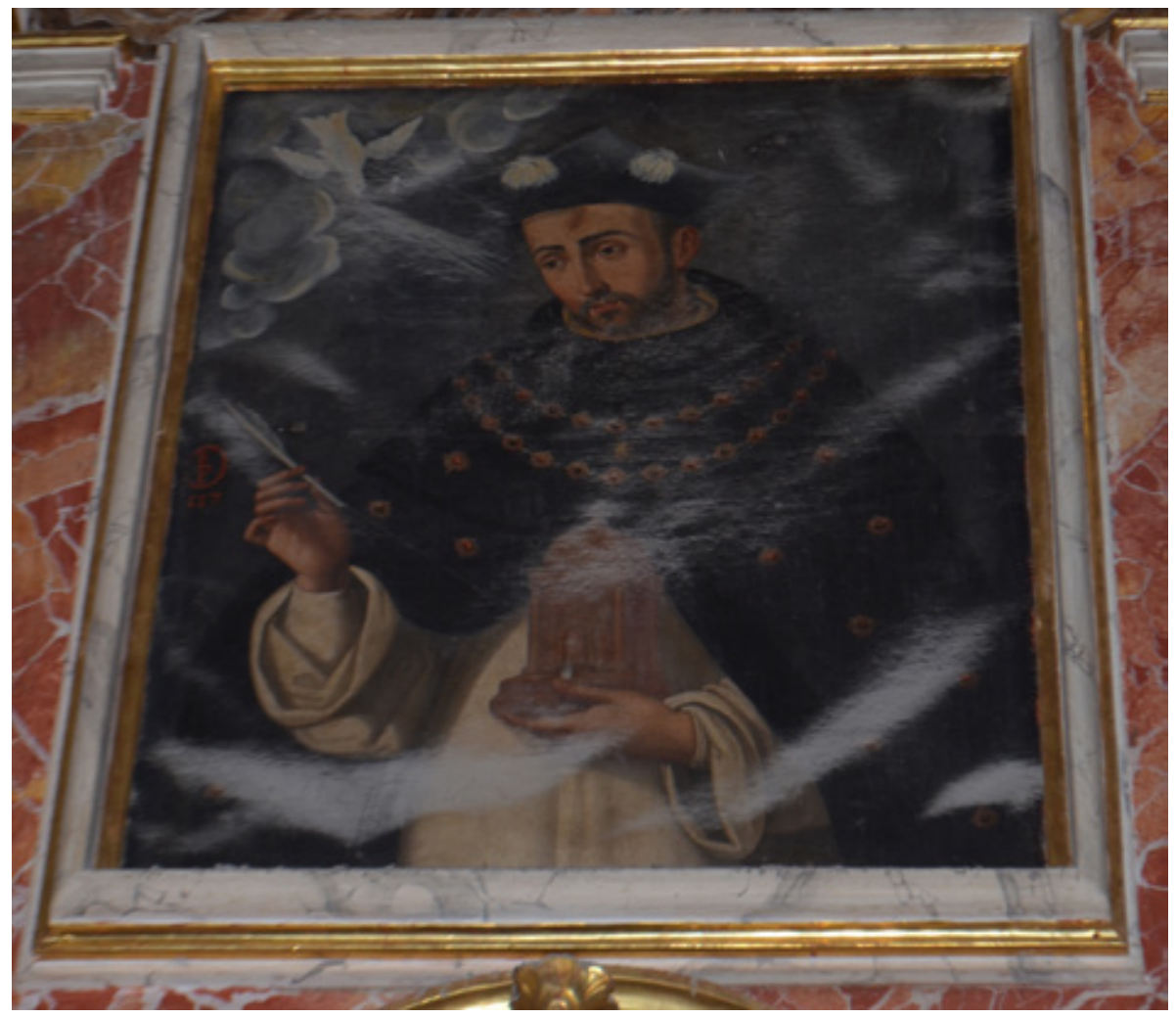

Figura 1. Francisco Pacheco, Santo Tomás de Aquino, 1617, iglesia de Santo Domingo de Guzmán, Sanlúcar de Barrameda (Cádiz). 


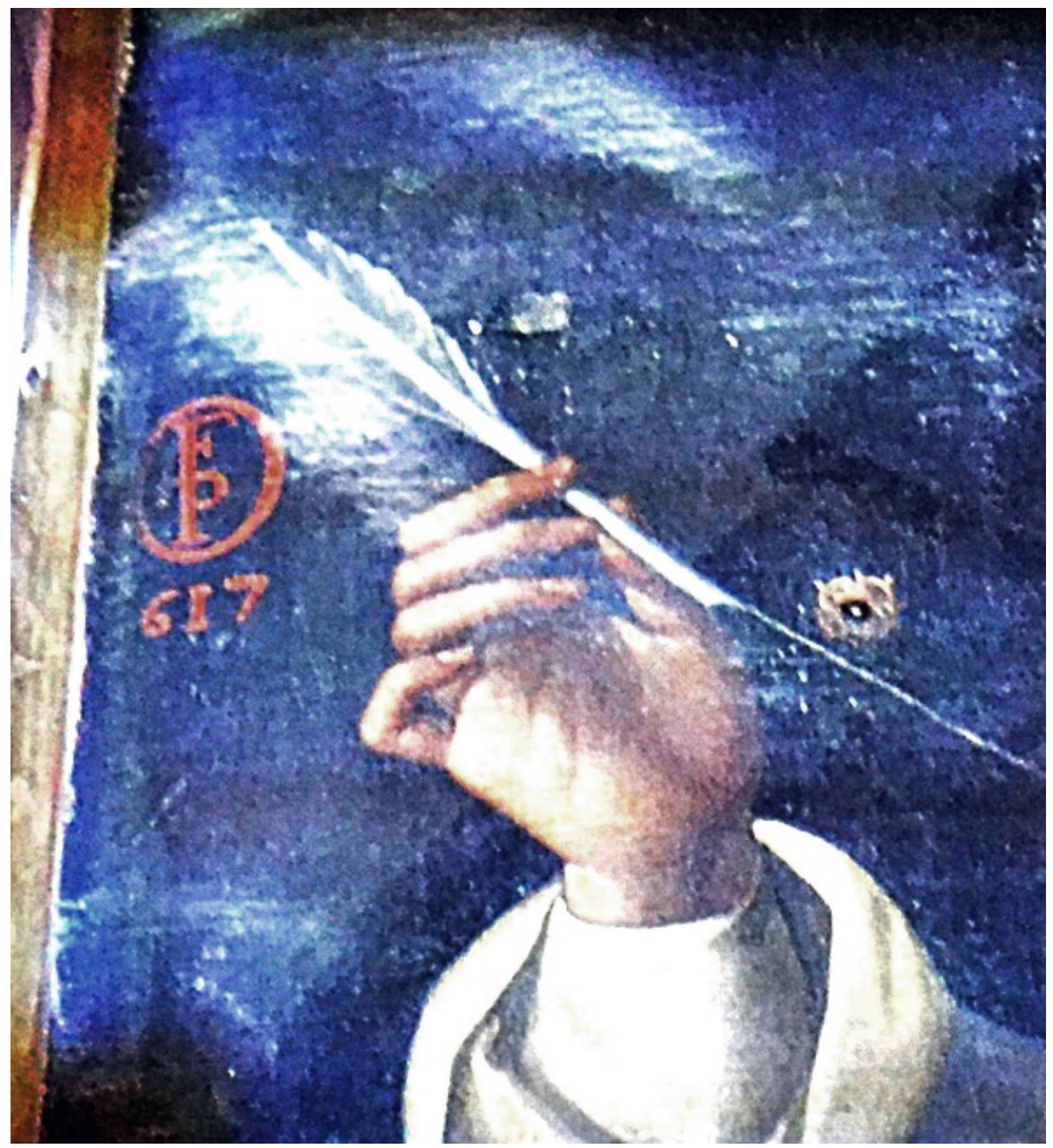

Figura 2. Francisco Pacheco, Santo Tomás de Aquino, detalle de la firma y fecha: "OFP 617”-“Opus Francisco Pacheco, 1617”-, 1617, iglesia de Santo Domingo de Guzmán, Sanlúcar de Barrameda (Cádiz). 


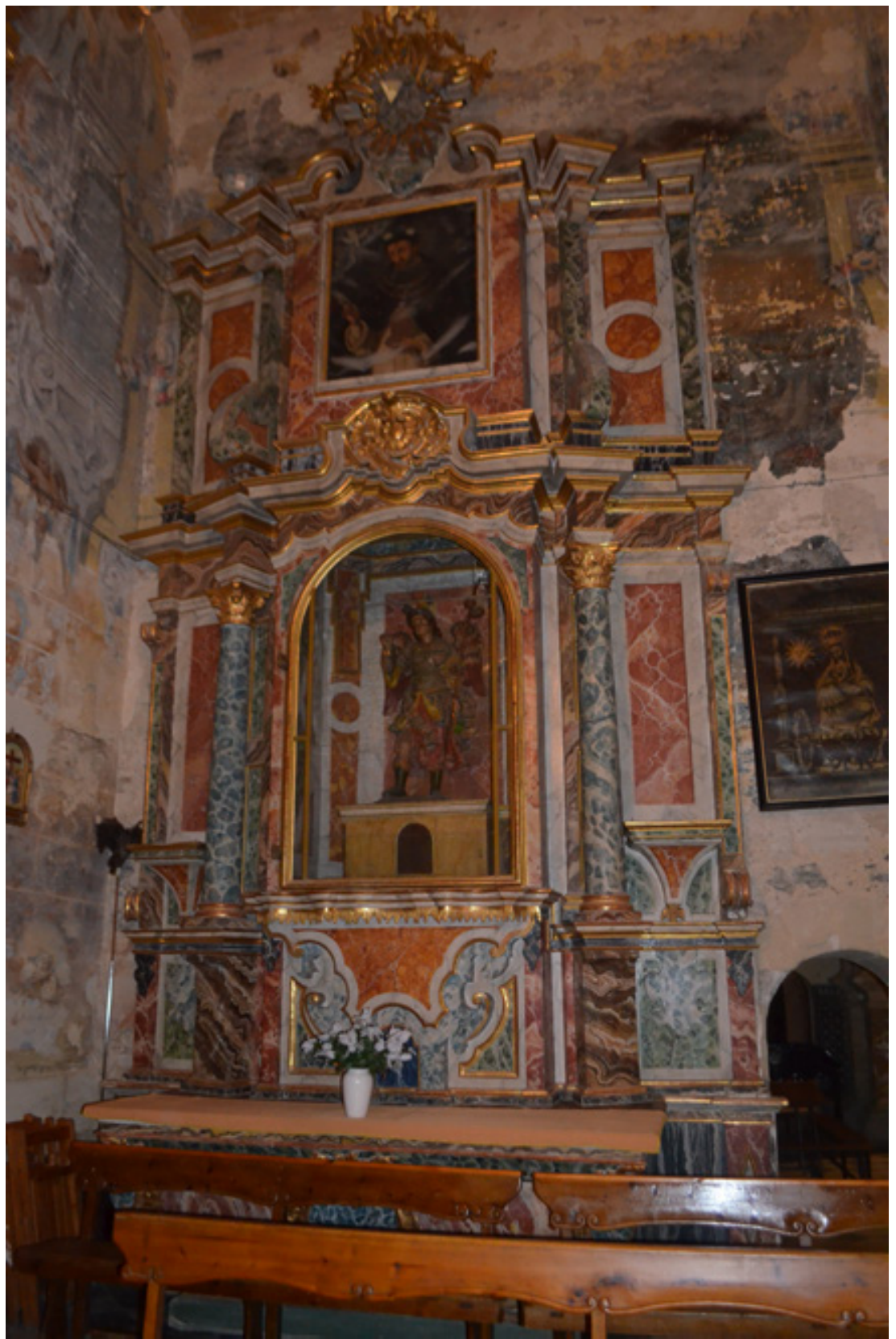

Figura 3. Retablo donde se encuentra el Santo Tomás de Aquino de Francisco Pacheco, iglesia de Santo Domingo de Guzmán, Sanlúcar de Barrameda (Cádiz). 